\title{
The Department of Engineering Cybernetics at NTNU: From 1994 Into the Future
}

\author{
Tor Arne Johansen Morten Hovd
}

Department of Engineering Cybernetics, Norwegian University of Science and Technology, NO-7491 Trondheim, Norway. E-mail: \{tor.arne.johansen, morten.hovd\} @itk.ntnu.no

\begin{abstract}
A short overview of the developments at the Department of Engineering Cybernetics at NTNU over the last 15 years is given. The vision of the department is to stay among Europe's most well recognized universities in control engineering, both with respect to education and research. The article discusses both how this goal has been achieved and how it will continue to be strengthened in the future.
\end{abstract}

Keywords: Engineering Cybernetics, Control Engineering, ITK, NTNU

\section{Introduction}

The years since 1994 have brought significant changes to the Department of Engineering Cybernetics (Institutt for teknisk kybernetikk, ITK) at the Norwegian University of Science and Technology (Norges teknisknaturvitenskapelige universitet, NTNU) in Trondheim, Norway. There are many new faces among ITK's employees, a strong focus on staying at the international leading edge in research, several new research areas, new structures and improvements to the Master and Doctorate education, strong internationalization, and strengthened collaboration with industry and within the university. This article gives some further perspectives on the evolution of ITK, and a glimpse into the future.

Internationally, there are few "engineering cybernetics" departments around, University of Stuttgart being one of the notable exceptions. The international counterpart is often a control engineering department which lacks the industrial computer system branch and application focus that in addition to control theory are the cornerstones of our department. We are proud to see that the brand "cybernetics" is now well established, with a strong position in the Norwegian industry and a wide recognition abroad.

\section{Education - From Sivilingeniør to the Master of Science degree}

Originally, the Norwegian Institute of Technology (Norges tekniske høgskole, NTH) offered a 4.5-year Sivilingeniør (Diploma Engineer) programme. This programme was continued for a short while after NTH was merged into NTNU in 1996. The last class following the 4.5-year programme graduated in the year 2000. ITK now offers a 5-year Master of Science (MSc) programme, and from 2001 our graduates started receiving the MSc degree. In addition to the 5 -year MSc programme, there is also a 2-year MSc programme which is open to students with a 3-year Bachelor degree from a regional college. Within the 5-year MSc programme, it is also possible to take the final year at the University Studies at Kjeller (UNIK).

Students graduating from the Department of Engineering Cybernetics have a solid theoretical background with a good understanding of systems thinking, feedback control, physics and mathematics. Furthermore, all students have in-depth knowledge of computer hardware, software, and real-time aspects. Our students are very attractive among employers due to their comprehensive and versatile education. It is fair to say that few other students have more diversified 


\begin{tabular}{ccc}
\hline & $\begin{array}{c}\text { Admitted } \\
\text { Year }\end{array}$ & $\begin{array}{c}\text { Admitted } \\
\text { 5-year MSc }\end{array}$ \\
2-year MSc \\
\hline 1997 & 80 & - \\
1998 & 97 & - \\
1999 & 96 & - \\
2000 & 129 & - \\
2001 & 109 & - \\
2002 & 100 & - \\
2003 & 100 & - \\
2004 & 83 & 14 \\
2005 & 98 & 16 \\
2006 & 70 & 15 \\
2007 & 90 & 13 \\
2008 & 100 & 10 \\
2009 & 95 & 10 \\
\hline
\end{tabular}

Table 1: Students admitted in Master Programs in Engineering Cybernetics at NTNU.

choices when entering the job market.

\subsection{Student numbers and admission requirements}

Until the early 2000s, the number of students applying for the Engineering Cybernetics programme was high, resulting in correspondingly high admission requirements.

After the "dot-com" bubble burst in 2000, the number of applications for all study programmes related to Information and Communication Technology (ICT) was affected, including the Engineering Cybernetics programme. The introduction of new programmes in what are currently considered "hot" areas have had a similar effect.

However, concerted efforts by both staff and students at ITK have reversed the downward trend in application numbers and admission requirements. The MSc programme in Engineering Cybernetics is challenging, and the department has therefore made it clear that admission requirements should not be set too low. It is preferred to maintain admission requirements at a level which indicates that the student is capable of pursuing this challenging course of study rather than inflating student numbers for reasons of funding.

\subsection{Courses and programme structure}

The transition into a 5-year MSc programme required a significant change in the programme structure and reorganization of the course contents. University guidelines required all courses in the new programme to be of equal size (4 courses per semester), all laboratory activities were integrated into ordinary courses, and some hard-core technology had to go in order to leave room for compulsory courses such as philosophy, team work, and technology management. This development lead to more cybernetics courses in the first two years of study than before, but also an overall reduction in the number of courses, resulting in more material being put into each course. In this way, the total number of courses offered by ITK has remained limited, which has given time for research for the department's scientific staff, and is consistent with our aim to provide cutting-edge, research driven education. This aim has wide support within NTNU.

The new programme structure that was imposed on all the engineering disciplines at NTNU thus provided an opportunity for a thorough review of the courses offered. Engineering Cybernetics is an enabling technology in most (if not all) industries, and our graduates therefore also end up in very different jobs and application areas. Consequently, the MSc programme aims to give a solid background in control and dynamical systems combined with industrial computing. A substantial number of courses are therefore compulsory and common to all students, with opportunities to specialize in specific application areas limited mainly to the two final years of the 5 -year programme. The interdisciplinary nature of the education is particularly evident through the close collaboration with the Department of Marine Technology on joint courses and study profiles in Marine Cybernetics, and the Department of Circulation and Medical Imaging on ultra-sound imaging courses and study profile in Medical Cybernetics.

The course format has got a more international flavor, with recognized international textbooks forming the basis of most courses, teaching in English to meet the needs of international students in some advanced courses, and the use of mid-term exams and grading of project and laboratory work. The need to have a good working knowledge of Norwegian terminology has lead to the strategic decision to rely on our own Norwegian textbook in the basic control engineering course.

To ensure educational quality, ITK has implemented student and internal evaluation of all regular courses. Results of these evaluations are reported to the department council and provides feedback for continuous improvement.

\subsection{Infrastructure, workshops and laboratories}

In the last few decades, there has been a clear trend in higher education that experimentation with real systems gets replaced by computer simulations. To some extent, this trend is also present at ITK. However, it 
is seen as important to still be able to perform real-life experiments both in education and in research, as well as to develop the students' practical skills and awareness. About $50 \%$ of the courses offered have integrated laboratory exercises, most notably:

- Instrumentation and PLC laboratories in both introductory and advanced courses.

- Robotics laboratory for the introductory cybernetics course.

- Real-time control laboratory used for computer control, real-time programming and embedded systems courses.

- Helicopter laboratory used in the linear systems and optimization courses.

- Computer hardware laboratory used in industrial computer systems courses.

In addition, project and master thesis work is often based on experimental work that involves building hardware and software, and all courses have computer simulation activities. Therefore, our department has both an electronics workshop with three permanent staff and a mechanical workshop with two permanent staff in addition to two permanent staff for computer services. The members of the technical staff are vital in the development, operation and maintenance of both educational and research laboratories. These research laboratories are described in Section 3.2.

\section{Research}

\subsection{Organization}

Since the 1990s the department has been organized in three main research groups:

- Process Cybernetics

- Motion Control

- Industrial Computer Systems

These groups have been involved in several large projects or cross-disciplinary activities and centers, where some of the main ones have been:

- PROST (1994-2002) - Strong Point Center in Process Systems Engineering, Trondheim, Norway. PROST was one of the first Strong Point Centers to be recognized by what was then the University of Trondheim in 1994. It consisted of faculty and PhD students in NTNU's Chemical Engineering department, Energy and Process Technology department, the Engineering Cybernetics department, as well as staff in the corresponding research groups in SINTEF.

- Strong Point Center in Marine Vessel Control (1998-2003) conducted research on control systems for maritime and offshore applications, including dynamic positioning.

- Petronics (2001-2005). In collaboration with Hydro, Shell, ABB, Scandpower and TU Delft, the objective was for NTNU to develop solutions for automatic control of oil wells and optimized oil production.

- Centre for Ships and Ocean Structures (CeSOS, 2002-2012) aims at developing fundamental knowledge about how ships and other structures behave in the ocean environment, using analytical, numerical and experimental studies. This activity is accomplished by integrating theoretical and experimental research in marine hydrodynamics, structural mechanics and automatic control.

- The Gas Technology Centre (2003-2012) forms a part of NTNU and SINTEF's Strategic Research Area Energy and Petroleum - Resources and Environment. The centre seeks to exploit the synergism of multidisciplinary research into the natural gas value chain.

- Strategic University Program for Computational Methods in Nonlinear Motion Control (2004-2009) investigated the design and analysis of nonlinear motion control systems based on computational methods.

- Centre for Research-based Innovation in Aquaculture Technology (CREATE, 2006-2014) is a consortium of leading research institutions and equipment suppliers for the aquaculture industry with a common focus to innovate technology, products and solutions to improve the grow-out phase of marine fish culture.

- Center for Integrated Operations in the Petroleum Industry (since 2006). Together with SINTEF and industrial partners, the IO Center conducts research, innovation and education within the IO field, to promote accelerated production, increased oil recovery, reduced operating costs and enhanced safety and environmental standards.

- Strategic University Program on Control, Information and Communication Systems for Environmental and Safety Critical Systems (20082012). This program will develop emerging and 
enabling technology for environmentally sustainable resources management and utilization. This goal includes ICT for environmental surveillance, spill detection and subsea repair, as well as new technology for renewable energy sources.

- The Gemini Centre for Advanced Robotics (since 2009), jointly with SINTEF, provides expertise within modelling, control and design of advanced robotic and production systems.

Although the research groups still remain the same, research activities now tend to be organized laterally in interdisciplinary centers leading to more of a matrix organization with respect to research.

ITK actively participates in EU-funded research. In addition to the research funding this provides, participation increases international visibility and strengthens international networks.

In 2001-2002 the Research Council of Norway conducted a review of 56 research groups at Norwegian universities and colleges in the ICT area. In the review, both the motion control and process cybernetics groups received the best grade "excellent", while the industrial computer systems group was graded "very good".

\subsection{Research laboratories and infrastructure}

One area where ITK has been more successful than most other universities during the last 15 years of research concerns the combination of advanced theory with real-world applications. State-of-the-art nonlinear control theory such as Lyapunov-based nonlinear and adaptive control design, nonlinear model predictive control, and nonlinear observers have been successfully implemented both in the department's own research laboratories and in full-scale experimental trials, products and facilities with our industrial partners. The use of experimental data for estimation and modelling of industrially relevant processes and systems has been a cornerstone in the research activities on process control, biomedical systems, motion control and fisheries and aquaculture.

Much research has been supported by in-house construction of dedicated experimental facilities and instruments, electronics and computers. The laboratory facilities and the effort of the electronics and mechanical workshops at the department have been instrumental to support many of the research activities, several of them at other locations at NTNU such as SeaLab and the Marine Cybernetics Laboratory basin, as well as with SINTEF Applied Cybernetics.

The key research laboratory facilities at the department during the last 15 years include the industrial robotics labs; a compressor lab; a nano-positioning lab; an underwater vehicle lab; the scale-model ships CyberShip 1, 2 and 3; the scale-model semi-submersible CyberRig 1; a navigation laboratory; the research vessel Balchazar; a snake robotics lab; and several laboratories for medical technology and aquaculture research.

\subsection{From Dr.ing. to PhD}

NTH and NTNU previously offered the Doktor Ingeniør (Dr.ing.) degree in the engineering and technology disciplines. More recently, this title has been rebranded with the internationally more common $\mathrm{PhD}$ title. Karl Petter Lindegaard, who graduated from ITK in September 2003, was the first to receive the new $\mathrm{PhD}$ degree from NTNU.

Until now, PhD candidates graduating from ITK have received their degrees in the rather non-descript area Information and Communication Technology. The department is pleased that future graduates will receive their degrees in Engineering Cybernetics, thus both making the subject of their specialization much more clear and raising the profile of the department.

NTNU gives an annual award (the Esso award) to the best $\mathrm{PhD}$ thesis in engineering and the best $\mathrm{PhD}$ thesis in science. PhD students at the Department of Engineering Cybernetics have received this highly recognized award several times during the last 15 years:

- Jann Peter Strand, Nonlinear Position Control Systems Design for Marine Vessels, 1999.

- Ole Morten Aamo, Modelling and Control of Fluid Flow and Marine Structures, 2002.

- Petter Tøndel, Constrained Optimal Control via Multi-Parametric Quadratic Programming, 2003.

- Roger Skjetne, The Maneuvering Problem, 2005.

Recruitment to the $\mathrm{PhD}$ programme has shifted into a majority of international candidates being admitted over the last years. We are pleased to observe that many - if not most - of them prefer to remain in Norway and choose to apply for employment in Norwegian companies after they complete their $\mathrm{PhD}$ degree.

\subsection{Publications}

The strategic importance of publishing the research results in the best international journals was fully recognized at ITK around 1990. This change lead to a more theoretical twist with appreciation of mathematical rigour in parts of the research activities, while at the same time the drive for practical relevance and proof by experiment prevailed. 


\begin{tabular}{ccc}
\hline Year & Completed PhD & Publications \\
\hline 1994 & 8 & 24 \\
1995 & 9 & 31 \\
1996 & 11 & 50 \\
1997 & 6 & 63 \\
1998 & 8 & 68 \\
1999 & 5 & 78 \\
2000 & 8 & 91 \\
2001 & 3 & 65 \\
2002 & 3 & 76 \\
2003 & 4 & 99 \\
2004 & 9 & 104 \\
2005 & 2 & 183 \\
2006 & 6 & 249 \\
2007 & 9 & 209 \\
2008 & 15 & 212 \\
2009 & 6 & - \\
\hline
\end{tabular}

Table 2: Number of Dr.ing./PhD degrees and publications authored by employees and students at ITK. Source: FRIDA.

As shown in Table 2, this development contributed to a strong increase in the number of reported publications $^{1}$, while the number of professors and PhD students remained fairly constant. In 2008 the department reported the highest number of publications per scientific staff among all engineering departments at NTNU. Employees at the department have over the last 15 years received several best paper awards in top ranked journals such as Automatica and IEEE Transactions on Control Systems Technology:

- J.T. Gravdahl and O. Egeland, Centrifugal Compressor Surge and Speed Control, IEEE Transactions on Control Systems Technology, Volume 7, pp. 567-579, 1999.

- J. P. Strand and T. I. Fossen, Nonlinear Passive Weather Optimal Positioning Control (WOPC) System for Ships and Rigs: Experimental Results, Automatica, vol. 37, pp. 701-715, 2001.

- K.Y. Pettersen, F. Mazenc and H. Nijmeijer, Global Uniform Asymptotic Stabilization of an Underactuated Surface Vessel: Experimental Results, IEEE Transactions on Control Systems Technology, Vol. 12, pp. 891-903, 2004.

\footnotetext{
${ }^{1}$ When interpreting the publication data one should have in mind that only after the early 2000s did the number of publications reported into this database actually have a direct effect on the department's budget, so there may be a tendency for under-reporting until then.
}

\begin{tabular}{lc}
\hline Year & External funding \\
\hline 2003 & $22 \%$ \\
2004 & $12 \%$ \\
2005 & $21 \%$ \\
2006 & $29 \%$ \\
2007 & $34 \%$ \\
2008 & $26 \%$ \\
$2009^{*}$ & $20 \%$ \\
\hline
\end{tabular}

Table 3: Percentage of funding being external. The number for $2009^{*}$ is a prediction.

\subsection{Innovation}

Publication of research results is being combined more often with securing intellectual property rights, which has also become more important on NTNU's agenda since Norwegian laws in this area was harmonized with European and international laws from 2003. The universities got a stronger position with respect to their employees for ownership of research results, but without interfering with the academic freedom to publish results or the ownership and exploitation rights of our external collaborators.

ITK has a long tradition with industrial spin-offs, which has continued with several students establishing new companies based on their own ideas developed during innovative projects and masters theses.

\subsection{Research funding}

Most doctorate students and temporary research staff (post-doctors and researchers) are funded externally, typically by the Research Council of Norway, companies, or other governmental or international research funding bodies. This funding has been reasonably stable over the years, although the statistics show significant variations from year to year, see Table 3 . The department is fully dependent on these external funds.

\section{Strategy and future plans}

The vision of the department is to stay among Europe's most highly recognized universities in control engineering, both with respect to education and research.

\subsection{Strengths and opportunities}

Most of the control engineering activities at NTNU are located at ITK, notwithstanding significant activities in both the Chemical Engineering and Marine Technology departments. This situation gives a strong and 
cohesive base for the control engineering activities at the university.

In contrast, at many international universities the control engineering activities are spread on several groups in the Electrical Engineering, Mechanical Engineering, Chemical Engineering, Aeronautical Engineering, and possibly also the Mathematics departments. Therefore, although ITK is a small department at NTNU, it is actually of considerable size compared to most international control engineering groups.

Control and automation technologies have previously been criticized for "stealing work from people". From the point of view of a high-cost country like Norway such criticism is definitely absurd. With today's globalized economy, there will always be workers willing to work for less in other parts of the world. For industrial production to stay in Norway, it therefore has to be performed very efficiently - which clearly points to the need for control and automation. It is our impression that this fact is now being grasped by employers and employees alike. Norwegian industry is therefore likely to increase their use of control and automation as a means of staying competitive.

Cybernetics is nowadays recognized more and more as an enabling technology for new products and services that completely rely on automatic control and monitoring. We see more often that products are designed with core functionality realized by automatic control, and no doubt the future will require more autonomy and advanced functionality that cannot be realized without cybernetic methods. Many researchers tend to agree that while control theory is a fairly mature field in general, there are tremendeous opportunities offered by combining advanced control theory with new interesting applications across all disciplines.

\subsection{Student recruitment and graduation}

While student recruitment has not faced any dramatic changes, it is getting more challenging and requires more and more attention in order to maintain our targets for admission. The department is actively involved in numerous recruitment and dissemination activities targeting different groups, and this activity will be strengthened in the years to come.

\subsection{Industrial collaboration}

A close cooperation with the industry, SINTEF and other research institutions, and government is of strategic importance for the department and its scientific staff. Collaboration takes place through adjunct professorships, joint research projects and research activities, supervision of $\mathrm{PhD}$ and Master students, guest lectures, and in many other ways. In order to strengthen the department's position as the prime source of highly qualified employees with MSc and PhD degrees in Norway, the links to Norwegian industry have to be developed further. It is the department's strategic target to remain the preferred research partner for Norwegian industry in this area.

\subsection{International collaboration}

Both research and education are international arenas, and NTNU has a particular national and international responsibility compared to the regional colleges and universities in Norway. Quality of research must be measured against international standards in peer reviewed journals, and must be competitive and relevant on a global scale. Almost all research projects and $\mathrm{PhD}$ student activities at the department involve some form of international collaboration, either with direct involvement and exchange of personnel with international partners, or through Norwegian companies operating internationally. Publication of results in international journals and conferences is established as a key indicator of quality and relevance of research. A significant number of Master students are seeking to take up to one year of the studies abroad, typically the fourth year of the 5-year program, with encouragement from the university.

\section{Acknowledgments}

Our colleagues at ITK have not only contributed to the department's excellence and being a great place to work and study, but also provided data, text and comments for this paper. 